\title{
Why Minimizing the Successful Story of Vaccines?
}

\section{Lang Pierre Olivier*}

Nescens Centre of Preventive Medicine, Clinique of Genolier, Genolier, Switzerland

Translational Medicine Research Group, School of Health, Cranfield University, Cranfield, United Kingdom

Vaccination is a powerful public health tool that has been of tremendous benefits in protecting vulnerable populations from common and/or life-threatening pathogens worldwide. The exact benefits of vaccination on the health of the world's peoples are really hard to exaggerate. With the exception of safe water, no other modality, not even antibiotics, has had such a major positive impact on morbidity and morbidity reduction and population growth [1]. With the introduction of several successful vaccines during the twentieth, major achievements included the development of the polio vaccine in the 1950s and the eradication of smallpox during the 1960s and 1970s have been obtained. While the last has contributed to avoid 300 million cases and probably saved 100 million lives [1], the incidence of poliomyelitis has been reduce by $100 \%$, and by $90 \%$ for diphtheria, tetanus, measles, mumps and rubella [2].

However, vaccines do not guarantee complete protection from a disease at any time or sometimes. This mainly depends on the vaccines immune system capacities and some people simply does not respond adequately or at all $[3,4]$. For example, older adults are commonly described to fail to respond proprely to antigenic stimuli compared to their younger counterparts [3]. Although the immunosenescence process greatly contributes to this less-than optimal immune response to vaccination this decline is however not uniform within this population [5], frailer individuals demonstrating the poorer responses [4]. While the exact benefit of vaccination in the global aged population is still widely debated, the overall body of evidence nevertheless suggests that vaccination is however beneficial [2]. Because healthy and active aging is the result of a lifelong practice of preventive behaviours, in addition to a balanced diet, lifelong learning, physical activity and appropriate screening, vaccination can also greatly promote healthy aging and quality of life. Consequently, not only annual influenza vaccination should be proposed to every adults aged 65 years or over but also diphtheria-tetanus booster doses, pneumococcal and herpes zoster vaccines, and even pertussis vaccination for those taking care of their grandchild aged $\leq 6$ months [3]. This is moreover true when the herd immunity effect is taken into account. Indeed, in addition to the direct benefits to vaccinated individuals, greater effect on analysing the impact on close contacts, neighbours, and at the community level have also been also demonstrated [3]. This has the effect of increasing the level of population (or herd) immunity and increasing the likelihood that susceptible individuals (i.e. those who are not or incompletely vaccinated or those in whom vaccination is contraindicated or considered as less effective) will not be infected.

Vaccines are designed and vaccination programmes timed to protect populations and nevertheless they arouse the distrust today. Even if they contributed to divide by 30 the mortality due to certain pathogens, vaccines are now considered with the greatest scepticism. Scandal of the hepatitis B vaccine and elaboration hastily some vaccine against the H1N1 pandemic that in addition was believed to induce Guillain Barré syndrome, were reasons which incited the public health to become more vulnerable to vaccination protest movements [6]. In 1998, the claim that the MMR vaccine played a causative role in autism created a controversy and led to a decrease in its use resulting of outbreaks and increased number of cases worldwide. Similar figures of the strong public fear of vaccination can be drawn for pertussis within countries where routine vaccination was dropped with a 115 and $400 \%$ increase in pertussis prevalence in non-immunized adolescent and adult populations. Similarly, the number of diphtheria cases in Europe has dramatically increased and this mostly among unvaccinated adolescent, adult and elderly populations [3]. This fear of vaccine has also led parents to strange and sometime illegal behaviours. Thus, a growing number of parents are scheduling varicella and influenza play dates (e.g. flu and pox parties) where their children share lollipops and trade germ-infected pyjamas and other items with people who claim to have infected children to spread the disease and avoid vaccinations [3]. Parents to make contact with these strangers used trendy social networking services, and give potentially infectious matters to food to their children with the hope they become ill. However, not only this probably does not transmit the disease effectively but it may also be a reliable method of transmitting other pathogens (i.e. hepatitis $B$, staphylococcal and group A streptococcal infections) that the parents never intended to expose their children to [7]. Consecutively, whether it is by negligence or by distrust, an increasing number of individuals, including high-risk group suffering from chronic health conditions, are not immunized any more. Finally, for many Vaccines Preventable Infectious Diseases (VPDs), vaccine coverage rates do not reach neither the WHO objectives nor the herd immunity thresholds and this in many developed countries [8]. As a result, some VPDs that we believed under-control are now re-emerging. Moreover some classic childhood VPD have become instead adolescent and adulthood diseases in the nonvaccinated population [3].

Together, these findings demonstrate that our current attitude towards vaccines have led to fundamental changes in the epidemiology of common VPD worldwide and the importance of a high vaccine coverage rate in newborns and infants, and the necessity to increase administration of booster doses in all adults. They also reflect a number of underlying healthcare, economic, cultural and/or political barriers to vaccinations that represent a considerable challenge to break down in the view of the tension between individual rights and public health [6]. For example, to the question, does every individual may or must have the choice? Mandate influenza vaccine to Health Care Workers (HCWs) was thought to be the best option for increasing their vaccine coverage rate. Indeed, despite knowing that vaccination is a patientsafety imperative, many healthcare professionals are not immunized against influenza [2]. Multiple reasons exist for HCW resistance to influenza vaccination, including cost, inconvenience, and fear of needles. Some of the more common bits of misinformation associated with influenza vaccine include a belief that one can get influenza from the vaccine, an assumption that influenza is a mild illness, and a fear of adverse effects associated with the vaccine. While hospitals mandating

*Corresponding author: Pierre Olivier Lang, Nescens Centre of Preventive Medicine c/o Clinique of Genolier-Route du Muids 3, Genolier $\mathrm{CH}-1272$, Switzerland, Tel: +41.22.366.90.00; Fax: +41.22.366.90.11; E-mail: polang@nescens.com

Received July 31, 2012; Accepted June 31, 2012; Published August 02, 2012

Citation: Olivier LP (2013) Why Minimizing the Successful Story of Vaccines? J Gerontol Geriat Res 2:e117. doi:10.4172/2167-7182.1000e117

Copyright: () 2013 Olivier LP. This is an open-access article distributed under the terms of the Creative Commons Attribution License, which permits unrestricted use, distribution, and reproduction in any medium, provided the original author and source are credited. 
vaccination for employees have raised the hackles of some unions and professional associations, these findings highlight the importance of educating HPW of the risks, benefits, and basic principles of vaccination [9]. Indeed HCW "willingness to be vaccinated" is critical since they are the advisers most trusted by the patients. Lack of information provided for health care workers about vaccines plays a key part in their likelihood to promote it to patients.

And you, as a HCW, are you updated with your influenza, hepatitis B (+/- hepatitis A), poliomyelitis, Measles-Mumps-Rubella (MMR) and Diphtheria-Tetanus-Pertussis (DTPa) vaccinations? As a physician, do you systematically offer influenza, pneumococcal and diphtheriatetanus-pertussis vaccines to all of your older patients?

\section{References}

1. Plotkin S, Orenstein W, Offit $P(2008)$ Vaccines. ( $5^{\text {th }}$ edn), Saunders.

2. Lang PO, Govind S, Michel JP, Aspinall R, Mitchell WA (2011) Immunosenescence: Implications for vaccination programmes in adults. Maturitas 68: 322-330
3. Lang PO, Aspinall R (2012) Immunosenescence and herd immunity: with an ever-increasing aging population do we need to rethink vaccine schedules? Expert Rev vaccines 11: 167-176.

4. Yao X, Hamilton RG, Weng NP, Xue QL, Bream JH, et al. (2011) Frailty is associated with impairment of vaccine-induced antibody response and increase in post-vaccination influenza infection in community-dwelling older adults. Vaccine 29: 5015-5021.

5. Govind S, Lapenna A, Lang PO, Aspinall R (2012) Immunotherapy of immunosenescence; who, how and when? Open Longev Sci 6: 56-63.

6. Poland GA, Jacobson RM (2011) The age-old struggle against antivaccinationists. N Engl J Med 364: 97-99.

7. Hambleton S, Arvin AM (2005) Chikenpox party or varicella vaccine? Adv Exp Med Biol 568: 11-24

8. WHO vaccine-preventable diseases monitoring system (2009). Global Summary.

9. Baeyens JP, Lang PO, Michel JP (2009) Willingness to vaccinate and to be vaccinated in adults. Aging Clin Exp Res 21: 244-249. 